To appear 2019 in the Oxford Encyclopedia of Morphology (ed. Rochelle Lieber)

\title{
Morphology and Language Documentation
}

\author{
Yuni Kim
}

\section{Summary}

What does it mean to document the morphology of a language, and how does one go about such a task? Most of the world's languages are arguably underdocumented, yet morphological generalizations often require large amounts of primary data: thousands of word forms could be needed to establish basic patterns of allomorphy, for example, or the structure of an inflectionclass system. Because of this, the major debates in the language documentation literature affect the field of morphology by shaping the nature of the data. A starting point is the idea that traditional methods of elicitation, often via translation from a contact language and inevitably requiring a patient speaker, can mask ingrained assumptions about the ontology of data and the wider context of linguistic research. Critical examination of these assumptions yields a wider range of possible approaches that can be drawn on to produce a corpus theorization (i.e., a rationale for the types of communicative events to be recorded) appropriate to each language situation. In particular, it has been argued that it is sometimes not ethical to collect language data in a decontextualized way that prioritizes (or appears to prioritize) the linguist's goals above speakers' goals, where those are not the same. Thus in morphology, where virtually everyone agrees that some type of elicitation is essential, creativity and flexibility are sometimes needed to address or modify research questions. Fortunately, documentary linguistics has seen significant advances in the theory and practice of data management, making it possible to work efficiently with data from a wide variety of recording-session structures.

Of equal interest are the reasons why a decontextualized approach may be undesirable even for the linguist's analytical purposes. The goal of "documenting morphology" is an abstract one; you can only really document word forms, and morphological structure is a product of analysis. From this fact arise a few problems. First, and even independently of the ethical issues referred to above, it is not always obvious what methods are most reliable for getting speakers to produce word forms or for understanding speakers' knowledge about them. Different methods have complementary pros and cons, so it is usually necessary to use a mix. When working with existing data, an appreciation of the complexities of the data gathering process is useful for developing a critical approach to the background contexts, strengths, and limitations of primary sources. Second, "documentation" implies a reasonable level of comprehensiveness. For many semantically or functionally defined phenomena, it is possible to make a cross-linguistically robust checklist that ensures that one has more or less covered the relevant territory. It is much less straightforward to compile an inventory of structures in any formal domain, particularly given cross-linguistic variation in morphological vs. syntactic vs. prosodic encoding of similar functional categories. In morphology, the linguist's inventory of phenomena often keeps expanding until nearly all grammatical constructions and large numbers of lexical items have been encountered. Again, this challenge can be addressed by using a mix of methods and genres to check that one has a correct understanding of at least the most commonly occurring patterns. Spontaneous speech tends to contain constructions that fail to show up in elicitation for reasons like pragmatics or interference from the contact language, while structured elicitation or metalinguistic work is needed to fully investigate the wordformation patterns within each of those constructions, or indeed (if the linguist is non-native) to get enough of a foothold to work with spontaneous speech at all. Checklists from the 
viewpoint of morphological typology tend to initially be most useful for monitoring and organizing, and later for filling gaps at a more advanced stage of research.

\section{Keywords}

linguistic fieldwork, field methods, documentary linguistics, descriptive linguistics, ethics, endangered languages

\section{Language documentation and language description}

In a broad sense, "documentation" refers to the general availability of information about a language. For a linguist, resources such as grammars or dictionaries might spring to mind - but a heavily theoretical article with just a few data illustrations would probably not. This intuition, that documentation is inherently data-rich, anticipates modern definitions of language documentation which are focused primarily on the data itself: "a lasting, multi-purpose record of a language" (Himmelmann 2006a: 1) or "the creation, annotation, preservation and dissemination of transparent records of a language" (Woodbury 2011: 159). Since the 1990s, language documentation - the critical study and theory of how to create records of languages, drawing on disciplines beyond linguistics - has been considered by a growing group of scholars to be a field of inquiry in its own right (see also Austin 2010). Its concerns include topics like ethnographically informed corpus design, the development of data collection methods, the annotation and archiving of linguistic data, and the relationship between research activities and their social, historical, and cultural contexts.

Language documentation thus centers around primary data, which can be defined as representations of individual communicative events. Such representations can include recordings, which are fairly direct representations at least of the audio or video aspects of the event; or more derived or indirect representations, such as transcriptions (Lehmann 2004: 180, Schultze-Berndt 2006: 214). The focus of documentary linguistics on primary data sets up a contrast with language description, which produces what we can call secondary data: analytical statements that generalize over multiple communicative events or are otherwise abstracted away from the immediate context of a single use (Good 2011: 215). Notably, products such as grammars and dictionaries fall under the definition of secondary data, and thus do not belong to language documentation in the strict sense.

The optimal balance of documentation and description in research on understudied languages is a matter of debate (see Berge 2010). Himmelmann (1998) draws a logical distinction between documentation and description in virtually all aspects, from methods, to aims, to results. He argues that documentation should be prioritized in order to ensure sufficient attention to the quality and quantity of primary data - in other words, to avoid the tendency to siphon disproportionate energy toward linguistic analysis (ibid.: 164) and the arguably redundant compilation of information that is extractable from the corpus. Instead, analytical statements can be included as annotations in the corpus to maximize the creation of knowledge with limited time and resources (2006a: 24). On the other hand, Woodbury (2003: 42) views grammars and dictionaries as being in an evolving dialectical relationship with the corpus; and Evans (2008) cites Craig (2001), Rhodes et al. (2006: 3-4) and others in arguing that the production of reference materials is a catalyst for new discoveries, allows us to assess the status of knowledge relative to the remaining gaps, and can be of symbolic and practical importance for communities. Crucially, all of these advances can inform and shape subsequent data collection. In particular, Evans (2008: 348) argues that decentralized annotations may "[fail] to pick up on the interactions between different subanalyses and [represent] the analytic claims as a miscellaneous catalogue rather than an organized whole", obscuring the kinds of bird'seye analytic breakthroughs that tend to crystallize only as the overall contours of a language's 
design gradually sharpen into focus. Nevertheless, linguists - particularly those interested in grammatical structure - must still consider Lehmann's (2001: 90) point, quoting Wilhelm von Humbolt, that because even the best descriptions are insufficient to allow the production of a novel native-like text, good documentation is essential "if one wants a lively representation of how the language really works"; see also Pawley (1993).

The main objective of this article is to explore what the complementarities and tensions between documentation and description mean for the relationship between morphology - the analytical enterprise of producing generalizations about word structure, formation, and relationships in languages - and the primary data of language documentation. For Gippert, et al. (2006: v), it is essential that "the interfaces between primary data and various types of analysis are made explicit and critically reviewed." This article is thus intended for various audiences whose work requires a general bridging of the conceptual gap between the structure of a morphological system and its individual, documentable word forms, including (though not limited to): linguists engaged in fieldwork or data collection who want to produce a description of a particular language's morphology, morphological theorists who use documentary materials produced by others in their research, and those involved in more holistic language documentation projects who want to improve the usability of their corpus for subsequent morphological study (as one of multiple possible purposes of the data, whatever its position on the current priority list).

In this article, "morphology" is used in a broad sense to refer to any aspect of word structure. "Word" is understood as a flexible abstraction over some prototypical properties, rather than a theoretical construct as such, given that the concept of the word is demonstrably problematic in many languages (Haspelmath 2011; Bickel \& Zúñiga 2017; Tallman \& Epps, in press). No particular divide or relationship is assumed between morphology and syntax, as this is an area of theoretical contention. That said, there is a cline of grammatical phenomena with the more typically morphological ones clustering at one end (boundedness, noncompositional semantics, lack of one-to-one correspondences between form and meaning, internally fixed and non-permutable structure, less recursion, etc.; see also Haspelmath 2011: 5 on common wordhood criteria), and most of the examples and discussion will be concentrated on these. However, many of the issues and techniques discussed will also apply equally to more prototypically syntactic aspects of linguistic structure, as the lack of an uncontroversial divide applies as much to methods as it does to ontology.

Building on the first definition of language documentation above, we can ask what principles are useful in designing a "lasting, multi-purpose record" of a language's morphology, in the sense of a dataset that would be usable for work on just about any morphological topic. Likewise, the non-trivial relationship between primary and secondary data means that "the creation, annotation, preservation and dissemination of transparent records" of a language's morphology is a complex task that is interpretable in multiple ways. The fact that no word form is ever a purely morphological object - it has a phonology, it has a syntax, and any individual documented instance of it takes place in some extralinguistic context - means that, in practice, there will usually not be a sole and isolable "morphological" part of the documentation. Data that seem best suited to some other purpose might also be used for morphological analysis, and, conversely, decisions about how to record data in formats well-suited for morphological analysis (e.g. paradigm elicitation) have to be considered in light of the overall goals of each documentation project and its stakeholders.

The structure of the article is as follows. In $\S 2$, we consider the place of morphologically-oriented data collection in the overall context of work with minority and endangered languages. The issues are largely ethical in nature, arising from the goals of the participants in any given documentation project, which may or may not be primarily linguistic in nature. We review suggestions and examples from the literature where different goals have 
successfully been reconciled. In $\S 3$, we discuss the advantages and disadvantages of specific techniques for recording word forms in various formats, ranging from translation-based elicitation to naturally occurring discourse. The concept of corpus theorization in terms of grammatical structure is also considered, with some concrete recommendations for morphological phenomena to check for. Finally, aspects of data management are briefly covered in $\S 4$.

\section{The place of morphology in language documentation projects}

Our overarching question, of how to produce documentation that can be used to describe a language's morphology, breaks down into a sequence of smaller questions: how to decide on the target content to be recorded, how to identify, create, and structure situations for recording in which speakers are likely to produce that content, and how to manage and organize data in a way that enables it to be described and analyzed.

Deciding on the target content, at least in broad terms, seems easy if one has a clear goal of collecting morphological data: one should record word forms representing as many of the language's structural possibilities as possible. However, especially in the case of understudied languages where resources are scarce and community goals relating to language work may be salient, decisions about target content cannot be made in isolation. Detailed aspects of linguistic structure are only one area of inquiry, whereas community members may assign greater importance to the study of culturally significant discourse genres, the preparation of pedagogical and/or practical reference materials, and other socially contextualized aspects of language (Mosel 2006: 68 inter alia). Even in cases where speakers are perfectly willing to focus on linguistic structure, Mithun's (2001) concept of "shaping the record" is an ever-present issue: an exclusive focus on grammar may not be the best use of limited resources if the language is endangered and the current project is likely to be the main documentation handed down to posterity.

The idea of corpus theorization, the concept makes a corpus "cohere or 'add up"" (Woodbury 2011: 161, Woodbury 2014: 21), is helpful for understanding the relationship between the documentation data and its uses in research. A corpus could be theorized in terms of its coverage of linguistic structure; but equally well its structure and content can be theorized in terms of discourse genres, social groups, or cultural topics. However, the commitment in language documentation to transparent, multi-purpose records means that the theorization of a corpus is not identical to its content as such. In this space between theorization and content, different sets of goals can often be negotiated and accommodated. Thus, for example, a genrebased theorization need not exclude careful attention to documenting linguistic structure, nor vice versa.

\section{$2.1 \quad$ Research models, ethics, and collaboration}

Three key concepts are frequently intertwined: research models, corpus design, and ethics. Obviously, research must be conducted ethically. It is now usually assumed that the most ethical research model is a collaborative one. Collaborative models of language work, as articulated by e.g. Cameron, et al. (1992), Czaykowska-Higgins (2009), Glenn (2009), Leonard \& Haynes (2010), and several papers in Grenoble \& Furbee (2010), emphasize the need to balance priorities depending on the diverse goals of everyone involved. Although definitions of "collaboration" can vary slightly, most have in common that speakers and other representatives of the language communities actively participate in formulating the direction and content of the project. Consequently, an ethically designed corpus may assign a minority role to (or even exclude) session formats such as list-like elicitation of isolated words and 
sentences that may be preferred by linguists as providing the most efficient and complete data for grammatical analysis. But every situation is unique, and so it is useful to ask to what degree research models and corpus design can legitimately vary, both individually and in their relationship to each other. The issue is of special interest to morphologists because morphological research tends to rely heavily on word forms taken out of their discourse, social, or cultural context, which many speakers and communities may find problematic. Therefore, some navigation is needed to avoid ethical pitfalls, while also making the most of opportunities that may be lost if one is not able to adapt a nuanced ethical framework to specific situations and participants.

Linguistic fieldwork raises a number of ethical concerns, which do not have a long history of being addressed appropriately; see e.g. Dwyer (2006), Macri (2010), and Rice (2012). The main concerns have to do with ways in which linguist-driven agendas and interactions risk disempowering speakers and communities. The prototypical conflict is that linguists are interested in decontextualized linguistic structure, eliciting often-unnatural content for narrow theoretical purposes rather than frequency of use, cultural relevance, or conversational authenticity. The resulting data may not be useful for speakers and communities, whose goals may include things like documentation of local oral traditions, development of writing systems and pedagogical materials, revitalization initiatives, or even just a reasonably accurate representation in the documentary record of how their language is spoken and used in the context of their daily lives. More generally, Stebbins (2012) highlights the pressures associated with conflicts of identity, roles, and worldviews when negotiating between academia and community life.

Since many projects are initiated by linguists, linguistic agendas may tend to prevail in the design of the project. Interactions between linguists and speakers and/or community members may be framed primarily in terms of the linguist's goals; Musgrave \& Thieberger (2007) discuss fundamental differences in approach, as well as the additional influences of funding sources. The framing or even mere presence of a language documentation project can contribute to discourses of commodification (Dobrin, Austin \& Nathan 2009) and/or rapid shifts in language ideologies, particulary among groups whose language is endangered (Hill 2006a: 127). The ethical danger is that an outside linguist could unwittingly participate in larger entrenched power asymmetries where privileged outsiders gain disproportionate benefit. When investments of time, resources, and energy by community members are viewed as primarily being of benefit to outside linguists, there can be an unfortunate reinforcement of insidious dynamics in the wider social context, most conspicuously the legacy of colonialism and its modern manifestations. The same is potentially true when speakers' control or say in the project is minimized in subtler ways. Mithun (2001: 49) stresses the importance of respecting speakers' implicit linguistic ontologies instead of dismissing information whose relevance for Western research paradigms is not immediately obvious. Another example is van Driem's (2016) attack on the ways in which certain culturally-specific aspects of Western ethics protocols can undermine a linguist's relationship with speakers.

For morphologists who get involved with minority-language data collection and find themselves working in the context of these ethical debates, an important question is whether elicitation of long lists of individual word forms is compatible with collaborative research. Virtually everyone agrees that elicitation is needed to study morphology. The most obvious and standard reason cited is that it would take an impossibly long time for every item in a paradigm to be uttered in spontaneous speech (e.g. Bowern 2008: 73). Articulating what is probably a common practice in the field, Payne (1997: 368-9) recommends elicitation as a primary data-gathering method for morphophonemics, derivational morphology, and the structural possibilities for inflection, while the semantics and function of different words forms can be explored with a "large body of text data, supplemented by elicitation where necessary." 
In its stereotypical form, elicitation is a linguist-driven activity. The speaker - who may have to be "trained" by the linguist to be "good" at it - may slip into a passive role of generating the forms requested by the linguist for purposes whose relevance may seem remote. It may be all too easy for the eager theoretician to conspicuously value some speakers' contributions more than others, if those speakers' particular skills coincide with the linguist's goals, like ability to generate paradigms (rather than being an acute observer of something else that may not be part of the immediate research agenda). The potential for a power asymmetry and non-collaborative dynamic - or even the appearance of one, to those observing a project from the outside - may raise red flags for the ethically aware linguist who is contemplating grammatical description.

One version of this discomfort is discussed by Crippen \& Robinson (2013) under the rubric of "lone-wolf" linguistics. They ask whether linguists' goals must always be "subordinate" to community projects, and argue that in the situations they describe, "there is nothing unethical about setting one's own research agenda and conducting linguistic fieldwork alone" (p. 132). The reply by Bowern \& Warner (2015), while disagreeing strongly with a number of Crippen \& Robinson's positions, sets out a varied series of "portraits" or "scenarios" (pp. 60-63) to demonstrate that the collaborative spirit must be understood in a more nuanced way in order to assess the ethics of any particular language project.

Notably, while the scenarios vary in how closely they conform to the prototype of community language activism, on a close reading they do all include some role or provision for analysis of linguistic structure (at a minimum, engagement with historical descriptions). Bowern \& Warner observe that speakers' goals are much more diverse than the production of "kindergarten language primers", and they are furthermore dynamic, with the possibility that linguists could collaborate in developing a vision for future language work (see also Dobrin 2008, Pérez-Báez 2017). The claim that ethical fieldwork can take many forms, in terms of the actual participation of different parties in different activities, echoes Leonard \& Haynes's (2010: 289) framing of collaboration as a "philosophy and approach rather than a set of guidelines about research roles and outcomes", and Rice's (2012) emphasis on adapting to different situations. It furthermore anticipates Dobrin \& Schwartz's (2016) proposal that collaborative approaches be situated within a more general practice of participant observation, which "offers a means for discovering what constitutes positive relations according to members of a host community" (p. 270), the outcomes of which may or may not include joint languagework projects of a kind suitable for a university's "research impact" portfolio. We can therefore consider ways in which ethically-designed documentation corpora can be useful for morphological description, and also in which morphological analysis can feed into a language community's priorities.

\section{$2.2 \quad$ Reconciling goals}

A cornerstone of modern documentary linguistics is the notion that we cannot foresee all possible future uses of the data (Mithun 2001: 53, Himmelmann 2006: 2). A corpus should therefore strive to contain as wide a variety of information as feasible, including linguistically embedded cultural information and authentic discourse genres (see e.g. Sherzer 1987, Amery 2009, Michael 2011), in addition to vocabulary and evidence for linguistic structure. Woodbury (2011) calls for the development of explicit corpus theorizations, both for the sake of internally comprehensive and coherent documentations, and also in order to anticipate future audiences. As a concrete example, Holton (2012) discusses the importance of language-documentation data at the Alaska Native Language Archive for current cultural research in non-linguistic topics like ethnoastronomy. Franchetto (2006) provides useful information on the kinds of language-documentation content that are most likely to be of interest to ethnographers. 
One of the main ways that these ideas interface with morphological documentation and description is represented by Hill's (2006b) analysis of possibilities for the integration of cultural information in descriptive grammars. An important facet of this is ensuring that all example words and sentences reflect "culturally appropriate usage" (p. 612), even if this means that the examples cannot be sanitized and simplified to reflect only the structural property under discussion. Similarly, Mithun (2007: 52) warns that overemphasis on specific grammatical points can result in a surfeit of artificial examples (of the type His father thinks that John hit Mary) that "[limit] the record not only of vocabulary, but also of larger patterns of expression." While cultural appropriateness is ideally confirmed by taking examples from spontaneous speech, this principle can also be incorporated into elicitation sessions that form part of the corpus, even if their primary role is to illustrate something like inflectional paradigms. By incorporating words that are salient in the local everyday context, and interweaving ethnographic and/or pragmatic discussion into wordlist-design sessions to improve the authenticity of the examples, a grammatically oriented part of the corpus can still serve multiple purposes. Potential future data-users should be kept in mind even in those situations where native speakers have no salient language goals but are happy to participate in the linguist's grammatical research.

Although the notion of adequacy in documentation (Berge 2010, Michael 2011) is often taken as an imperative to situate linguistic data in their sociocultural context to rectify asymmetries caused by the grammar-focused bias of much linguistic data collection, the opposite is also relevant. Grinevald (2007: 39) reminds us that "no matter what the expanded scope of most projects on endangered languages today, the linguists will always be the academic researchers primarily responsible for the analysis of the linguistic structure of those languages". Insight into overt principles of grammar can end up being useful for communities, even for language revitalization programs whose main goal is to build everyday communication skills. Warner, et al. (2007) offer examples of the benefits of morphological research for the Mutsun tribe of California. In Mutsun, singular clitic pronouns were more frequent than independent-word pronouns, so the clitics are being encouraged in revitalization in order for modern language use to more closely resemble that of the ancestors. Furthermore, the Mutsuns are using productive morphology to create new lexical items needed for modern life, following principles of noun-noun compounds and nominalizing morphology. Similarly, Amery (2001: 184) reports on the creation of new words in Kaurna based not only on documentary attestations of derivational morphology, but even the creation of new derivational affixes via reduction of independent lexical items, based on novel but plausible pathways of grammaticalization.

It is also possible to pursue the linguist's goals in a way that is meaningful to community members, thereby adding value to the project. For example, Yamada (2007: 267) outlines an approach for grammatical description where speakers play a dominant role in deciding on names for linguistic phenomena, rather than passively being told by a linguist what structures their language has. She also describes a case where community teaching needs drove the choice of which morphological construction to analyze in further detail, and how linguistic training with the main consultant meant that the speaker's knowledge could be successfully foregrounded in the research. These methods work at rectifying the asymmetries of authority, and power over knowledge, that can exist in elicitation or other grammatically focused sessions; further techniques will be discussed below in §3. More generally, Rice (2011: 194) recounts how grammatical insights arose in the context of working with speakers on community-based projects. For example, morphophonological tonal alternations in Dene came to light during work on a dictionary project, and speaker-produced texts from a writing workshop provided the main impetus for solving a problem in plural-nonplural alternations in number marking. Relatedly, linguists can benefit from reflecting on what Linell (2005) and 
Moreno Cabrera (2008) have called the "written language bias" in linguistics, in order transcend those blinkers and be receptive to insights from the perspective of speakers not trained in the same tradition.

Having recognized that academic and practical goals are not always in conflict, we return to the undeniable fact that they do often differ; and so a further point can be made that different does not mean mutually exclusive. Evans (2008: 342) proposes that different goals can be distributed across the life cycle of a documentation project, through "time-linked clusters" of different activity types. The corollary, as he points out, is an ethical principle that "field languages require long-haul commitments." Similarly, Woodbury (2011: 175) cites Wilkins (1992) in highlighting the serendipitous and unpredictable nature of language work, where the conditions for pursuing certain goals may present themselves at unexpected times, necessitating flexibility in timescales and workplans.

\subsection{Summary}

Language documentation projects differ widely in the kinds of people involved; their backgrounds, approaches, and goals; and their roles and relationships with each other in the context of the work. When evaluating the ethical and scientific validity of project design or data collection methods, any realistic assessment will need to take various parameters into account. Arguably, some of the ethical controversies in the fieldwork literature are due to perceived under- or overgeneralization of guidance. Interactions that are problematic in one situation may be perfectly fine in another, although caution is always advisable since one does not necessarily know in advance, or indeed even in retrospect, what the dynamics of the situation are or were. The emerging consensus is that what is general is a decision-making framework, not the specific decisions that are made. Even when they are not engaged in a language documentation project sensu stricto, it is advisable for morphologists to be aware of this backdrop when gathering primary data from understudied languages.

\section{$3 \quad$ Data collection}

Assuming that one has established the ethical viability of a morphologically targeted part of the documentation that is at least semi-scripted, i.e. some form of elicitation session, there are still many issues to figure out. This section will focus mainly on the process of figuring out the structural issues of word forms (paradigm cells) exist, and what they are (individual manifestations and subgroups thereof. From the perspective of creating a multipurpose corpus, it is imperative to get as much information as possible about the semantics and function of the word forms, but the main issue highlighted here is the nontrivial problem of documenting the word forms themselves, in a useful format that allows them to be analyzed and compared. This section will survey some of the guidance available in fieldwork manuals and related works, with more detail to be found in the original sources (for example Samarin 1967; Abbi 2001; Vaux, Cooper \& Tucker 2006; Crowley 2007; Bowern 2008; Chelliah \& de Reuse 2011).

\subsection{Techniques for eliciting word forms}

"Elicitation" is a deceptively broad term, covering a range of metalinguistic activities from translating a word list from a contact language, to open-ended conversations about grammatical structures that may take place in the target language. I will use the term in an even wider sense of getting speakers to produce word forms in their language, even if it is not explicitly in the context of a metalinguistic discussion. In this sense, there is a continuum between elicitation and other "staged communicative events", defined by Himmelmann (1998: $185)$ as "communicative events that are enacted for the purpose of recording". 
A common way to gain initial information about a language, and more specifically for morphological purposes, the basic categories of exponence that manifest themselves in the word, is elicitation via translation from a contact language. This might proceed along the lines of asking for basic lexical items, and trying to figure out how grammatical distinctions of the contact language are realized (if they are at all) in the target language. This can be enriched with some typological knowledge to ask about word forms that are not morphologically distinct in the contact language, but can be described - if not always easily conveyed (e.g. first person inclusive versus exclusive when using English as the contact language). The existence of morphosyntactic categories can be checked by consulting typology-based overviews of meanings that are potentially grammar-encoded, such as the Lingua questionnaire (Comrie \& Smith 1977), as well as Payne (1997), which gives greater emphasis to structural possibilities.

Translation-based elicitation is not the only way to approach the structure of a language: native-speaker linguists will already have engaged in some introspection, while non-native linguists may gain basic competence via monolingual immersion, asking speakers in an openended way to provide words and phrases in certain semantic fields (Mosel 2006: 77), or going straight to text collection and start to acquire knowledge inductively by reviewing the material with a native speaker. Many linguists will use a mixture of these methods to get an initial lay of the lexical and grammatical land. In many cases, as well, there is some previous literature on the language family (if not on the specific language itself), which will give some clues about morphological categories to look for.

These other activities are important, because the pitfalls of translation-based elicitation are many; see $\$ 3.2$. Ideally, then, the data can be confirmed (or gotten in another way entirely in the first place) by other techniques, one set of which is labelled by Mosel (2012a: 82), following Samarin (1967) and others, as "non-translational elicitation". Mosel identifies six types, building on Samarin (1967) and Kibrik (1977); see also the classifications in Chelliah \& de Reuse (2011: chapter 12) and Bohnemeyer (2015). They are all ways of furnishing a context to prompt the speaker to fill in an appropriate word or produce an appropriate utterance within which a target form may be observed.

- Substitution involves taking a phrase or sentence and asking how it would be said with some variation in the context, e.g. TAM-related parameters, different lexical item, etc., that would cause one or more words to be replaced with a different form, but without prompting the speaker with a direct translation of the target form.

Variations of substitution are:

- the sentence-completion task (self-explanatory as such, although the exact presentation of a task to speakers is often tricky); and

- transformational elicitation, where a prompt in one construction is converted by the speaker into a different construction. For example, TAM forms could be elicited by providing verbs in one TAM category and having the speaker convert them into another.

Two other techniques that are more exploratory, i.e. not always suitable for eliciting specific target forms but still providing reasonably authentic material with potential for eliciting morphological alternations, are:

- requests for paraphrases, and

- open-ended requests for speakers to create example sentences based on a specific lexical item.

The last category, paradigmatic elicitation, is likely (in practice) to involve a combination of the preceding techniques. I take "paradigm" to refer broadly to any 
juxtaposition of utterances that differ minimally along some structural dimension, whether in the morphology or syntax. Most fieldworkers will have had the experience that it is difficult, if not impossible, to elicit paradigms in a format that goes in a straight and orderly way from the speaker's mouth into pre-drawn cells and tables in the field notebook (Chelliah \& de Reuse 2011: 383), unless one is working with a rare speaker who particularly enjoys this task. Bowern (2008: 94) gives examples of how substitution and sentence-completion questions can be used to fill in paradigm gaps. She also recommends that early identification of principal parts, i.e. the unpredictable cells in the paradigm from which other cells can be predicted, is convenient; although of course one does not want to abuse this shortcut before being sure of the system. An additional recommendation, implicit in the way that the techniques are presented as well as in the advice on inventing stories (ibid: 95) to keep paradigms from being too boring, is that it is not necessary to elicit all the forms of one word before moving on to the next word. It can be more engaging to elicit a list of many words all in the same form, then move on to a different morphological category and elicit all the words again, in a different form, and so on. Alternatively, one can still go word-by-word but take lots of breaks, or make more effort to vary multiple aspects of the frame sentences in ways that do not compromise the identity of the target form. Vaux, et al. (2006: 233-235) provide illustration and discussion of these options, as well as tips on organizing one's field notebook for paradigm elicitation. ${ }^{1}$

Among other data types, Lüpke (2009) gives an overview of semi-structured tasks that can be used to elicit communicative events for recording; see also Hellwig (2006) and Majid (2012) on non-linguistic stimuli. These includes things like picture-only stories or series of photographs which speakers can talk about using the resources of their native language. And, certainly in any type of authentic spontaneous discourse, which may be recorded for purposes other than grammatical analysis, one is bound to find morphological forms that can fill in gaps or uncover the existence of new categories. Mosel (2006: 87) observes that different genres of texts can favor different morphological constructions. More broadly, Mithun (2001: 53) Chelliah (2001: 156), and others observe that the pragmatics of spontaneous speech and varied discourse types can necessitate the marking of morphological categories that are not relevant in controlled elicitation contexts. Once known about, these categories can then be explored more thoroughly via more targeted elicitation techniques, or metalinguistic discussion. The fact that morphological categories will often only come to light in texts or spontaneous speech is a strong argument for broadening the data types in the corpus.

\subsection{Pitfalls}

The reliability of elicited data, in the sense of being representative of authentic usage in the target variety, cannot be taken for granted. Below are some examples of situations in which word forms uttered by a native speaker, even in spontaneous speech, may be influenced by specific factors and thus deviate from the forms that linguists or communities would consider most relevant for their goals. While these phenomena are interesting in and of themselves, they should be considered by those doing the documentation, as well as by researchers who are using data that may have been collected under atypical situations. The frequency of translationbased elicitation in linguistic research does imply that the method is not totally futile.

\footnotetext{
${ }^{1}$ A reviewer points out that a narrow interpretation of the term "paradigm elicitation" may be understood as excluding elicitation aimed at syntagmatic issues of e.g. permutability and ordering of elements, which are obviously relevant for morphological issues of affix order and combinations. Most of the techniques discussed under the umbrella of "paradigm elicitation" are useful any type of linguistic investigation that targets structurally defined sets of specific forms.
} 
Nevertheless, this is in part because many consultants come into contact with linguists either in, or by virtue of familiarity with, Western educational contexts where such tasks may be familiar, and in part because translation requests do often succeed in prompting native speakers to say something. The questions and doubts revolve around the reliability of that something.

Mosel (2012a: 82) summarizes the main points raised by Abbi (2001), Chelliah (2001), Bowern (2008), and others in this regard. Most of them have to do with the potential for miscommunication due to ambiguity or differing interpretations of the contact language, lack of direct translational equivalents between the two languages, and more direct interference from the contact language. Another factor is the general difficulty of conveying the nature of the highly unnatural task being requested. Grinevald (2007: 56) exhorts the reader to never use translation-based elicitation as a primary method with new consultants. Translation is cognitively taxing under the best of circumstances, and literal rather than pragmatically appropriate translations are awkward and may distort the cultural, or even linguistic authenticity of the data (Mithun 2001: 52). A reviewer emphasizes that translation should only be attempted if consultants have extensive experience with texts.

Structures which do not translate well between languages, or are otherwise hard to explain, are particularly prone to being under-detected. A speaker's null response to a contactlanguage gloss aimed at a specific category may in some cases reflect problems with the gloss, rather than the absence of the desired morpheme. Rice $(2001: 238,246)$ recounts the difficulty of studying verb forms in Slave, one of which even (erroneously) appeared to be marginal and unproductive, until English glosses were found that could be used to unlock the constructions with other speakers. Chelliah \& de Reuse (2011: 390) discuss some of the difficulties of eliciting tense-aspect-mood forms. On the discourse level, Mithun (2001: 47) relates problems with eliciting Central Pomo evidentials, since they are subtler than English adverbials and thus possibly untranslatable even via periphrasis. A parallel can be drawn with Cup'ik affective suffixes, which are frequent in discourse but disappear in English translations (Woodbury 1998: 251), and Cree obviative marking, which disappears in elicitation contexts (Cook \& Mühlbauer 2006).

The most obvious type of contact-language influence is the potential for eliciting calques that are either unnatural, or exist side-by-side with a native construction that is more difficult for the speaker to access in the context of spontaneous translation. This category of pitfall must also be considered more widely in light of the locally dominant language, even in sessions conducted monolingually in the target language; this latter scenario is especially salient with endangered languages. Evans (2001: 263) cites the case of Ngiyambaa, described by Donaldson (1980: 115), where the last speakers used constructions calqued from English rather than the native morphology. Interestingly, the speakers moved back toward the native constructions after remembering and using them in the elicitation context.

There is also the phenomenon of "linguist-directed speech." If the linguist is not seen as a fluent native speaker, the native speakers being recorded may simplify grammatical structures or otherwise produce speech that may sacrifice naturalness for comprehensibility. For example, Vallejos (2014) reports that Kokama speakers used bare morphemes when talking to her, since the morphology of the language is generally optional. While the recorded structures were still grammatical, any morphological analyses or descriptions based on this form of speech (e.g. claims about the lack of morphologically complex words) would clearly be incomplete. Linguist-directed speech is a particular issue when the research relies primarily on a single speaker, or on multiple speakers who can only be worked with individually, as is often the case with endangered languages. The phenomenon is not limited to outside linguists: Evans (2001: 266) describes a case of semi-speaker directed speech in Kayardild.

Relatedly, there are possible effects of individual-level attrition (see Schmid 2011 for the most complete overview) as well as community-level, obsolescence-related variation 
(Dorian 2001). While the latter are legitimate linguistic codes and worthy of study in their own right (Evans 2001: 259), their structure may diverge in many ways from what was spoken a generation or two earlier. Palosaari \& Campbell (2011) provide an overview of obsolescencerelated changes, which include loss of morphology and various kinds of under- and overgeneralization; see Maiden (2004) for a case study of Dalmatian.

Lastly and on a somewhat different theme, there is a danger of metalinguistic priming in repetitive elicitation (Bowern 2008: 102): in English, if a speaker were asked to say "singsang", and "ring-rang", it would be all too easy to follow this with "ping-pang" (rather than "pinged"). Mithun (2014: 34) further argues that particularly in derivational morphology, analogical forms created by speakers, judged as valid (whether marginally or fully) but for whatever reason not attested in the spontaneous part of the corpus, should be distinguished from forms that are more established in the language and in the culture.

\subsection{Corpus theorization for morphological structure}

So far we have focused on corpus theorization in terms of discourse genres, including the dynamic of verbal interaction during the elicitation sessions that are key to getting adequate data on a language's morphology. We can now take a more systematic look at the corpus theorization in terms of target morphological structures. As mentioned above, a basic approach is to determine what kinds of morphosyntactic and pragmatic categories are realized by morphological means in the language, and proceed to collect grammatically defined paradigms for each: e.g. all person-number combinations in a given tense, for verbs; or all possible combinations of gender and case for nouns, etc. And, new forms will inevitably be revealed serendipitously in different discourse types, and these can be followed up with elicitation. At more advanced stages of research, typological and theoretical perspectives can be a great aid in building on what is already known about the language in order to discover variations and elaborations of basic structures (e.g. Rice 2006); the volumes edited by Shopen (2007) are a particularly useful collection.

Yet, if the composition of a dataset is driven primarily by morphosyntactic distinctions, a number of morphological phenomena - those arising from lexical distinctions or more arbitrary morphological structure - can be missed. The problem is a deeper one, which is that elicitation produces word forms, not a structural analysis, and so, overwhelmingly, morphological structures can only be inventoried via abstractions over the data rather than being directly queriable. You generally cannot ask a speaker, for example, whether there are any verbal inflection classes that you have not covered. The undefined nature of the space to be explored is a perennial problem in grammatical description (Woodbury 2003: 39). A checklist or questionnaire about morphological structures (e.g. "does the language have infixes?") is not always helpful for telling one where to look in order to answer the question. By contrast, it is more common with syntactic questionnaires to be able to construct potentially relevant stimuli, since there is more frequently a more predictable association between form and function (e.g. "does the language permit verb-phrase ellipsis?"). Another way to state this problem is that the tension between onomasiological (function-to-form) and semasiological (form-to-function) approaches, familiar in grammaticography (Ameka, Dench \& Evans 2006), is reflected in the cycle of data gathering and data analysis that precede the writing-up of a grammar or other description. And at the extreme end of this cycle, the word-internal phenomena with form, but little to no apparent meaning or function ("morphology by itself" in the sense of Aronoff 1994 or "deviations from biuniqueness" as discussed by Haspelmath (2011): inflection classes, featurally incoherent syncretisms, multiple exponence, etc.) usually have to be noticed as a product of analysis before more data can be gathered in a targeted way. 
The core of the issue, and the reason why extensive language data (of the kind that might be gathered in a long-term documentation project) is crucial for morphology, is encapsulated by Brown \& Hippisley's (2012: 45) characterization of what constitutes a "full morphological model" of a language: "complete sets of forms of lexemes and associated features relevant for syntax." Of course, the possibility of "completeness" is dubious in either morphology or in syntax when one is dealing with productive and/or recursive phenomena. In any case, recent conceptualizations of morphological typology in terms of morphology-internal parameters and complexity (Brown 2010, Stump \& Finkel 2013) highlight the usefulness and interest of extensive data on paradigms, where feasible. Brown (2015) lists several morphological areas where large (if not "complete") amounts of data are needed due to potential lexical unpredictability: inflectional classes, stem classes, deponency, and syncretism. Possibilities for the improved integration of documentation databases with typologicallyoriented databases such as those described by Brown, et al. (2009) for several of these topics are an area for future development. Already, the design of such databases is informative for the types and quantity of data that are needed for a language to be included in studies of the respective phenomena.

To the phenomena mentioned by Brown, we could add the less transparent aspects of affix order and morpheme cooccurrence restrictions (see e.g. Inkelas 1993, based on Anceaux 1965; Manova 2015). Especially in non-agglutinating languages, it is necessary to test many combinations of morphosyntactic features to reveal portmanteau morphs, cases of contextual allomorphy, opaque paradigmatic relations, and the like (Blevins 2016). A corpus of spontaneous speech is not likely to contain anything near a full set of the desirable combinations. Going even further, cases of variable affix ordering inherently require multiple attestations of specific combinations, ideally from multiple speakers. Examples include free prefix ordering in Chintang (Bickel, et al. 2007), emerging variable ordering of suffixes in Murrinhpatha (Mansfield 2015), and a single locus of prefixal vs. suffixal placement variability within the otherwise invariant mobile-affix system of Huave (Kim 2010).

From another angle, with the understandable emphasis in morphological fieldwork on approaching categories through morphosyntax, a fact easily overlooked is that the morphological domains of phonological processes (levels, strata) may appear to be nonisomorphic with morphosyntactic constituents (Inkelas 2014, Bermúdez-Otero 2018). To the extent that this is true, there is potential evidence for a parallel constituent structure, regardless of whether it is ultimately analyzed as prosodic (Schiering, Bickel \& Hildebrandt 2010), syntactic in some non-obvious way, or truly morphological. This can be tested by examining known phonological processes one at a time, and examining forms of all conceivable morphological composition where the phonological structural description obtains, to see if the process applies. Lastly, on the topic of division-of-labor issues in grammatical analysis, a further reason to gather data from large amounts of lexical items is to have enough phonological environments to determine whether allomorphy is due to regular phonological processes or should be considered as suppletive; and if suppletive, whether phonologically, lexically, or otherwise conditioned. To take some examples of the latter, the debate on Romansh allomorphy between Anderson (2013) and Maiden (2017) is instructive for the types of data on which analyses can turn, and Mithun (2014: 32) highlights questions that would remain unanswered if certain infrequent stem-initial vowels could not be observed in combination with an alternating prefix.

The feasibility of systematic data collection, at the level of detail required to investigate the topics discussed in this subsection, will clearly vary, especially in light of $\$ 2$ and the previous material in $\S 3$. With a metalinguistically keen and talented speaker, in a social context that permits significant grammatical research in tandem with the data collection, more will be possible. But even if one is only able to record speakers who like to tell stories, one can make 
the most of the available data through through diligent management and flexible, queriable structures based on principles of corpus linguistics (see Mosel 2014; several papers in Seifart, et al. 2012). This, and other concerns, brings us to the next section.

\section{$4 \quad$ Data handling}

The desirability of preserving data in a transparent format, and making it accessible for whatever purposes it can serve in the future, is independent of the scope and design of the corpus. Thus, Woodbury (2011: 178) makes the point that elicited data can still constitute valuable documentation if it is properly annotated and archived. A good example is the Terrence Kaufman collections at AILLA (Archive of the Indigenous Languages of Latin America), which contain extensive material on 119 languages, much of which was gathered via elicitation and questionnaires.

There are many reasons to curate one's data and make it as accessible as possible (considering the wishes of the speakers). For documentation data to serve any future purposes, people need to be able to use it. In Thieberger \& Berez's (2012: 91) analogy, coherent data management is to future research as solid foundations are to a house. Even data that are recorded primarily for a specific project, rather than explicitly as language documentation, are likely to be of interest to the language community and future linguists, particularly if the language is endangered. It is important to note that accessibility is not the same as availability. An untranscribed, untranslated shoebox of recordings with idiosyncratic metadata could be available to the public, but very few people would be able to use the information. Nowadays, widely available software programs such as ELAN are standardly used to facilitate multi-tiered annotations. The integration of multi-tiered annotations with a lexical database is a particularly powerful tool for morphology, since glosses, the production of interlinearized text, and other products can be largely automated. A potential example is FLEx with ELAN, despite the currently limited functionality of FLEx for this purpose, as pointed out by a reviewer. For example, Mithun (2014: 28) illustrates a five-tier structure for presenting glossed and translated passages from morphologically complex languages, which could easily be outputted with an appropriate annotation and software setup such as an XML-based system (see Michailovsky, et al. 2014 for an example).

Further detailed advice on topics like best recording practices, transcription and annotation, metadata structures, workflow, etc. is available elsewhere (e.g. Bird \& Simons 2003, Austin 2006, Schultze-Berndt 2006, Bowern 2011, Good 2011, Thieberger \& Berez 2012, along with other sources on the Further Reading list) and need not be repeated here. Nevertheless, a few themes from the critical literature around data management can be highlighted for the purpose of considering the relationship between morphological research and language documentation. For linguists who wish to combine documentary and descriptive/analytical work, especially within the context of employment in the modern academy, one of the trickiest issues is that of achieving balance between data gathering, data organization, and activities around analysis and publication. In particular, data organization including activities such as databasing, annotating, preparing materials for archiving - is timeconsuming and typically undervalued.

However, there is growing awareness of the importance of this work within linguistics. In 2010-2011, the Linguistic Society of America passed a Resolution Recognizing the Scholarly Merit of Language Documentation, which promotes the consideration of primarydata archives, electronic databases, and other documentation outputs as scholarly contributions. New types of publications are emerging, such as guides to documentation corpora (e.g. Salffner 2015, Caballero 2017) and published datasets that can be cited (see Berez-Kroeker, et al. 2017). The development of norms for citing sources of linguistic data, on a par with those for citing 
analyses or theoretical ideas (Berez-Kroeker, et al. 2018a) is an essential component of bringing about an ethos where the creation of usable documentation data is valued.

The movement toward citation of primary data is part of a more general push for scientific integrity in the form of transparency and reproducibility in linguistics. BerezKroeker, et al. (2018b: 6-7) argue that the current norms of descriptive and theoretical linguistics do not incentivize sufficient transparency about the methods used to collect data or the sources that could be used to verify it. They cite Thieberger (2009), Maxwell (2012), and Gawne et al. (2017) in calling for standards of data attribution and accessibility that would enable linguistic research to be independently verified; see also Mosel (2012b), who gives specific advice on the use of regular expressions for searching corpora.

In line with this, reasonably organized and annotated data should be deposited in professional archives wherever possible. Like the rest of documentary linguistics, models of archiving have also been evolving rapidly in recent years; for overviews, see Trilsbeek \& Wittenburg (2006), Conathan (2011), as well as the the historical synthesis and comprehensive annotated bibliography of Henke \& Berez-Kroeker (2016). Archiving is no longer a static, unidirectional, one-off depositing of material. Instead, it has the potential to be an interactive and ongoing process of resource creation (Moore 2006). "Thick" interfaces (Nathan 2006) enable presentation of data in user-friendly formats, and there is an increasing movement toward "participant-driven"(Garrett 2014) and "community-based" archiving (Linn 2014), where speakers and communities collaborate in the design and content of the archived collection. The concept of progressive archiving (Nathan 2013) encourages depositors to submit small amounts of material as they become ready, in order to build up a collection over time - rather than wait for decades for a magnum opus which may or may not eventually be forthcoming. In all of this, there is a possibility for feedback and for updating previously deposited material as new information comes to light.

An increasingly common adage in language documentation is to not let the best be the enemy of the good (e.g. Evans 2008: 343). We cannot transcribe everything, and our databases cannot be perfect nor complete. Some effort at making data transparent and accessible is far better than no effort. Similarly, while familiarity with technical and organizational bestpractice recommendations can vastly enhance the quality of a documentary collection, Nathan (2004) and Dobrin, Austin \& Nathan (2009) remind us that "archivism" - a focus on form rather than quality and substance of linguistic data - also has its downsides. Overall, the main point is that data management recommendations are relevant for all linguists who collect primary data, even if (as may be the case with some morphologists) their work does not fit the prototype of long-term, field-based collaborative projects with community language activists resulting in sociolinguistically rich corpora of naturalistic communicative events.

\section{Conclusion}

Since the 1990s, the interdisciplinary field of language documentation has developed a critical approach to collecting and using data from lesser studied (often minority and/or indigenous) languages. Taking into account ethnographic aspects of language and the social backgrounds against which linguistic fieldwork is done, this literature argues that documentation projects should aim to create culturally contextualized corpora of naturalistic communication events. Such corpora should be suitable for multiple future purposes - only one of which is the investigation of grammatical structure. This creates a complex relationship between language documentation and the study of morphology in particular, since morphology is arguably the linguistic subfield most reliant on decontextualized elicitation as a data collection method. Yet, clearly, there is a symbiosis: meaningful documentation cannot exist without some degree of morphological analysis, and morphological theories depend on primary language data, whose 
existential validity - as well as usefulness for other purposes - depend on having been collected in a responsible, sensitive, and informed way. This article has surveyed ways in which a basis for morphological analysis can be laid throughout the processes of corpus design, data collection, and data management, as one of many possible goals that can be mutually compatible and even mutually reinforcing within a project of language documentation and description.

\section{Further Reading}

Austin, Peter K. \& Julia Sallabank. 2011. The Cambridge Handbook of Endangered Languages.

Chelliah, Shobhana \& Willem de Reuse. 2011. Handbook of Descriptive Linguistic Fieldwork. Dordrecht: Springer.

Gippert, Jost, Nikolaus P. Himmelmann \& Ulrike Mosel (eds.). 2006. Essentials of Language Documentation. Berlin: Mouton de Gruyter.

Grenoble, Lenore \& N. Louanna Furbee. 2010. Language Documentation: Practice and Values. Amsterdam: Benjamins.

Nakayama, Toshihide \& Keren Rice (eds.). 2014. The Art and Practice of Grammar Writing. Honolulu: University of Hawaii Press.

Newman, Paul \& Martha Ratliff (eds.). 2001. Linguistic Fieldwork. Cambridge University Press.

Nida, Eugene A. 1949. Morphology: The descriptive analysis of words. Ann Arbor, MI: University of Michigan.

Payne, Thomas. 1997. Describing Morphosyntax: A guide for field linguists. Cambridge University Press.

Rehg, Kenneth \& Lyle Campbell. 2018. The Oxford Handbook of Endangered Languages. Oxford: Oxford University Press.

Seifart, Frank, Geoffrey Haig, Nikolaus P. Himmelmann, Dagmar Jung, Anna Margetts \& Paul Trilsbeek (eds.). 2012. Potentials of Language Documentation: Methods, analyses, and utilization. Language Documentation \& Conservation Special Publication No. 3. Honolulu: University of Hawai'i Press.

Thieberger, Nicholas (ed.). 2012. The Oxford Handbook of Linguistic Fieldwork. Oxford: Oxford University Press.

\section{Links to Digital Materials}

Archive of the Indigenous Languages of Latin American - https://www.ailla.utexas.org Endangered Language Archive - https://elar.soas.ac.uk

The Language Archive (including the DoBeS Archive) https://archive.mpi.nl/?openpath=node: 77915

Language Documentation and Conservation (journal) - http://nflrc.hawaii.edu/ldc/

Language Documentation and Description (journal)

http://www.elpublishing.org/publications

\section{References}

Abbi, Anvita. 2001. A Manual of Linguistic Fieldwork and Structures of Indian Languages. Munich: Lincom Europa.

Ameka, Felix, Alan Dench \& Nicholas Evans (eds.). 2006. Catching Language: The Standing Challenge of Grammar Writing. Berlin: Mouton de Gruyter. 
Amery, Rob. 2001. Language planning and language revival. Current Issues in Language Planning 2(2-3): 141-221.

Amery, Rob. 2009. Phoenix or relic? Documentation of languages with revitalization in mind. Language Documentation and Conservation 3(2): 138-148.

Anceaux, J. C. 1965. The Nimboran Language: Phonology and Morphology. 'S-Gravenhage: Martinus-Nijhoff.

Anderson, Stephen. 2013. Stem alternations in Swiss Rumantsch. In S. Cruschina, M. Maiden \& J. Smith (eds.), The Boundaries of Pure Morphology: Diachronic and synchronic perspectives, 8-23. Oxford: Oxford University Press.

Aronoff, Mark. 1994. Morphology By Itself: Stems and Inflectional Classes. Cambridge, MA: MIT Press.

Austin, Peter. 2006. Data and language documentation. In J. Gippert, N. Himmelmann \& U. Mosel (eds.). Essentials of Language Documentation, 87-112. Berlin: Mouton de Gruyter.

Austin, Peter. 2010. Current issues in language documentation. Language Documentation and Description 7: 12-33.

Berez-Kroeker, Andrea, Lauren Gawne, Barbara F. Kelly \& Tyler Heston. 2017. A survey of current reproducibility practices in linguistics journals, 2003-2012. Available online at https://sites.google.com/a/hawaii.edu/data-citation/survey.

Berez-Kroeker, Andrea, Helene N. Andreassen, Lauren Gawne, Gary Holton, Susan Smythe Kung, Peter Pulsifer, Lauren B. Collister, The Data Citation and Attribution in Linguistics Group, \& the Linguistics Data Interest Group. 2018a. The Austin Principles of Data Citation in Linguistics. Version 1.0. Available online at http://site.uit.no/linguisticsdatacitation/austinprinciples.

Berez-Kroeker, Andrea L., Lauren Gawne, Susan Kung, Barbara F. Kelly, Tyler Heston, Gary Holton, Peter Pulsifer, David Beaver, Shobhana Chelliah, Stanley Dubinsky, Richard P. Meier, Nick Thieberger, Keren Rice \& Anthony Woodbury. 2018. Reproducible research in linguistics: A position statement on data citation and attribution in our field. Linguistics 56(1): 1-18.

Berge, Anna. 2010. Adequacy in language documentation. In L. Grenoble \& N. L. Furbee (eds.), Language Documentation: Practice and Values, 51-66.

Bermúdez-Otero, Ricardo. 2018. Stratal phonology. In S.J. Hannahs \& A. Bosch (eds.), The Routledge Handbook of Phonological Theory, 309-340. Oxford: Oxford University Press.

Bickel, Balthasar, Goma Banjade, Martin Gaenzsle, Elena Lieven, Netra Prasad Paudyal, Ichchha Purna Rai, Manoj Rai, Novel Kishore Rai, \& Sabine Stoll. 2007. Free prefix ordering in Chintang. Language 83: 43-73.

Bickel, Balthasar \& Fernando Zúñiga. 2017. The 'word' in polysynthetic languages: phonological and syntactic challenges. In M. Fortascue, M. Mithun, \& N. Evans (eds.), The Oxford Handbook of Polysynthesis, 158-186. Oxford: Oxford University Press.

Bird, Steven \& Gary Simons. 2003. Seven dimensions of portability for language documentation and description. Language 79: 557-582.

Blevins, James P. 2016. Word and Paradigm Morphology. Oxford: Oxford University Press.

Bohnemeyer, Jürgen. 2015. A practical epistemology for semantic elicitation in the field and elsewhere. In M. R. Bochnak \& L. Matthewson (eds.), Methodologies in Semantic Fieldwork, 13-46. Oxford: Oxford University Press.

Bowern, Claire. 2008. Linguistic Fieldwork: A practical guide. Palgrave Macmillan.

Bowern, Claire. 2011. Planning a language-documentation project. In P. Austin \& J. Sallabank (eds.), The Cambridge Handbook of Endangered Languages, 459-482. Cambridge: Cambridge University Press. 
Bowern, Claire \& Natasha Warner. 2015. 'Lone Wolves' and Collaboration: A Reply to Crippen \& Robinson (2013). Language Documentation \& Conservation 9. 59-85.

Brown, Dunstan. 2010. Morphological typology. In J.-J. Song (ed.), The Oxford Handbook of Linguistic Typology. Oxford University Press.

Brown, Dunstan. 2015. Modelling inflectional structure. In M. Baerman (ed.), The Oxford Handbook of Inflection, 275-295. Oxford: Oxford University Press.

Brown, Dunstan \& Andrew Hippisley. 2012. Network Morphology. Cambridge: Cambridge University Press.

Brown, Dunstan, Carole Tiberius, Marina Chumakina, Greville Corbett \& Alexander Krasovitsky. 2009. Databases designed for investigating specific phenomena. In M. Everaert, S. Musgrave \& A. Dimitriadis (eds.), The Use of Databases in CrossLinguistic Studies, 117-153. Berlin: Mouton de Gruyter.

Caballero, Gabriela. 2017. Choguita Rarámuri (Tarahumara) language description and documentation: a guide to the deposited collection and associated materials. Language Documentation \& Conservation 11: 224-255.

Cameron, Deborah, Elizabeth Frazer, Penelope Harvey, M. B. H. Rampton \& Kay Richardson. 1992. Researching language: Issues of power and method. New York, NY: Routledge.

Chelliah, Shobhana. 2001. The role of text collection and elicitation in linguistic fieldwork. In P. Newman \& M. Ratliff (eds.), Linguistic Fieldwork, 152-165. Cambridge: Cambridge University Press.

Chelliah, Shobhana \& Willem de Reuse 2011. Handbook of Descriptive Linguistic Fieldwork. Dordrecht: Springer.

Conathan, Lisa. 2011. Archiving and language documentation. In P. K. Austin \& J. Sallabank (eds.), The Cambridge Handbook of Endangered Languages, 235-254. Cambridge: Cambridge University Press.

Cook, Clare \& Jeff Mühlbauer. 2006. The behaviour of obviation in elicitation. In H. C. Wolfart (ed.), Actes du 37ème congrès des algonquianistes, 103-129. Winnipeg: University of Manitoba.

Craig, Colette. 2001. Encounters at the brink: Linguistic fieldwork among speakers of endangered languages. In O. Sakiyama (ed.), Lectures on Endangered Languages vol. 2: From Kyoto Conference 2000, 285-314. Kyoto: Endangered Languages of the Pacific Rim.

Crippen, James A. and Laura C. Robinson. 2013. In Defense of the Lone Wolf: Collaboration in Language Documentation. Language Documentation \& Conservation 7: 123-135.

Crowley, Terry. 2007. Field Linguistics: A beginner's guide. Oxford University Press.

Czaykowska-Higgins, Ewa. 2009. Research models, community engagement, and linguistic eldwork: Reflections on working within Canadian indigenous communities. Language Documentation \& Conservation 3(1). 15-50.

Dobrin, Lise. 2008. From linguistic elicitation to eliciting the linguist: Lessons in community empowerment from Melanesia. Language 84(2). 300-324.

Dobrin, Lise, Peter Austin \& David Nathan. 2009. Dying to be counted: the commodification of endangered languages in documentary linguistics. Language Documentation and Description 6: 37-52.

Dobrin, Lise \& Saul Schwartz. 2016. Collaboration or participant observation? Rethinking models of 'linguistic social work'. Language Documentation \& Conservation 10: 253277.

Donaldson, Tamsin. 1980. Ngiyambaa: The Language of the Wangaaybuwan. Cambridge: Cambridge University Press. 
Dorian, Nancy. 2001. Surprises in Sutherland: linguistic variability amidst social uniformity. In P. Newman \& M. Ratliff (eds.), Linguistic Fieldwork, 133-151. Cambridge: Cambridge University Press.

Dwyer, Arianne. 2006. Ethics and practicalities of cooperative fieldwork and analysis. In J. Gippert, N. Himmelmann \& U. Mosel (eds.). Essentials of Language Documentation, 31-66. Berlin: Mouton de Gruyter.

Evans, Nicholas. 2001. The last speaker is dead - long live the last speaker! In P. Newman \& M. Ratliff (eds.), Linguistic Fieldwork, 250-281. Cambridge: Cambridge University Press.

Evans, Nicholas. 2008. Review of Essentials of Language Documentation. Language Documentation \& Conservation 2(2): 340-350.

Franchetto, Bruna. 2006. Ethnography in language documentation. In J. Gippert, N. Himmelmann \& U. Mosel (eds.). Essentials of Language Documentation, 183-211. Berlin: Mouton de Gruyter.

Garrett, Edward. 2014. Participant-driven language archiving. In D. Nathan \& P. Austin (eds.), Language Documentation and Description, vol. 12: Special issue on language documentation and archiving, 68-84. London: SOAS.

Gawne, Lauren, Barbara F. Kelly, Andrea L. Berez-Kroeker \& Tyler Heston. 2017. Putting practice into words: The state of data and methods transparency in grammatical descriptions. Language Documentation \& Conservation 11: 157-189.

Gippert, Jost, Nikolaus P. Himmelmann \& Ulrike Mosel (eds.). 2006. Essentials of Language Documentation. Berlin: Mouton de Gruyter.

Glenn, Akiemi. 2009. Five dimensions of collaboration: Toward a critical theory of coordination and interoperability in language documentation. Language Documentation \& Conservation 3(2): 149-160.

Good, Jeffrey. 2011. Data and language documentation In P. K. Austin \& J. Sallabank (eds.), The Cambridge Handbook of Endangered Languages, 212-234. Cambridge: Cambridge University Press.

Grenoble, Lenore \& N. Louanna Furbee (eds.). 2010. Language Documentation: Practice and Values. Amsterdam: Benjamins.

Gries, Stefan. \& Andrea L. Berez. 2017. Annotation in/for corpus linguistics. In Nancy Ide \& James Pustejovsky (eds.), Handbook of linguistic annotation, 379-409. Berlin: Springer Verlag.

Grinevald, Colette. 2007. Linguistic fieldwork among speakers of endangered languages. In O. Miyaoka, O. Sakiyama \& M. Krauss (eds.), The Vanishing Languages of the Pacific Rim, 35-76. Oxford: Oxford University Press.

Haspelmath, Martin. 2011. The indeterminacy of word segmentation and the nature of morphology and syntax. Folia Linguistica 45(1): 31-80.

Hellwig, Birgit. Field semantics and grammar-writing: Stimuli-based techniques and the study of locative verbs. In F. Ameka, A. Dench \& N. Evans (eds.), Catching Language: The Standing Challenge of Grammar Writing, 321-358. Berlin: Mouton de Gruyter.

Henke, Ryan \& Andrea L. Berez-Kroeker. 2016. A brief history of archiving in language documentation, with an annotated bibliography. Language Documentation \& Conservation 10: 411-457.

Hill, Jane. 2006a. The ethnography of language and language documentation. In J. Gippert, N. Himmelmann \& U. Mosel (eds.). Essentials of Language Documentation, 113-128. Berlin: Mouton de Gruyter.

Hill, Jane. 2006b. Writing culture in grammar in the Americanist tradition. In F. Ameka, A. Dench \& N. Evans (eds.), Catching Language: The Standing Challenge of Grammar Writing, 609-628. Berlin: Mouton de Gruyter. 
Himmelmann, Nikolaus. 1998. Documentary and descriptive linguistics. Linguistics 36: 161195.

Himmelmann, Nikolaus. 2006. Language documentation: What is it and what is it good for? In J. Gippert, N. Himmelmann \& U. Mosel (eds.). Essentials of Language Documentation, 1-30. Berlin: Mouton de Gruyter.

Holton, Gary. 2012. Language archives: they're not just for linguists anymore. In F. Seifart, et al. (eds.), Potentials of Language Documentation: Methods, analyses, and utilization. Language Documentation \& Conservation Special Publication No. 3. Honolulu: University of Hawai'i Press.

Inkelas, Sharon. 1993. Nimboran position class morphology. Natural Language and Linguistic Theory 11(4): 559-624.

Inkelas, Sharon. 2014. The Interplay of Phonology and Morphology. Oxford: Oxford University Press.

Kibrik, Aleksandr. 1977. The Methodology of Field Investigations in Linguistics: Setting Up the Problem. The Hague: Mouton.

Kim, Yuni. 2010. Phonological and morphological conditions on affix order in Huave. Morphology 20(1): 133-163.

Lehmann, Christian. 2001. Language documentation: a program. In W. Bisang (ed.), Aspects of Typology and Universals, 83-97. Berlin: Akademie Verlag.

Lehmann, Christian. 2004. Data in linguistics. The Linguistic Review 21(3/4): 275-310.

Leonard, Wesley Y \& Erin Haynes. 2010. Making "collaboration" collaborative: An examination of perspectives that frame linguistic field research. Language Documentation \& Conservation 4. 268-93.

Linell, Per. 2005. The Written Language Bias in Linguistics: Its nature, origins, and transformations. London \& New York: Routledge.

Linn, Mary. 2014. Living archives: a community-based language archive model. In D. Nathan \& P. Austin (eds.), Language Documentation and Description, vol. 12: Special issue on language documentation and archiving, 53-67. London: SOAS.

Lüpke, Friederike. 2009. Data collection methods for field-based language documentation. Language Documentation and Description 6: 53-100.

Macri, Martha. 2010. Language documentation: whose ethics? In L. Grenoble \& N. Furbee (eds.), Language Documentation: Practice and Values, 37-48. Amsterdam: Benjamins.

Maiden, Martin. 2004. Into the past. Morphological change in the dying years of Dalmatian. Diachronica 21: 85-111.

Maiden, Martin. 2017. Romansh allomorphy (Again!). In C. Bowern, L. Horn \& R. Zanuttini (eds.), On Looking Into Words (And Beyond): Structures, relations, analyses, 190-210. Language Sciences Press.

Majid, Asif. 2012. A guide to stimulus-based elicitation for semantic categories. In N. Thieberger (ed.), The Oxford Handbook of Linguistic Fieldwork, 54-71. Oxford: Oxford University Press.

Manova, Stella. 2015. Affix Ordering Across Languages and Frameworks. Oxford: Oxford University Press.

Mansfield, John. 2015. Morphotactic variation, prosodic domains and the changing structure of the Murrinhpatha verb. Asia-Pacific Language Variation 1(2): 163-189.

Maxwell, Mike. 2012. Electronic grammars and reproducible research. In S. Nordhoff (ed.), Electronic Grammaticography, 207-234. Language Documentation \& Conservation Special Publication No. 4. Honolulu: University of Hawai'i Press.

Michael, Lev. 2011. Language and culture. In P. K. Austin \& J. Sallabank (eds.), The Cambridge Handbook of Endangered Languages. Cambridge: Cambridge University Press. 
Michailovsky, Boyd, Martine Mazaudon, Alexis Michaud, Séverine Guillaume, Alexandre François, \& Evangelia Adamou. 2014. Documenting and researching endangered languages: the Pangloss collection. Language Documentation and Conservation 8: 119-135.

Mithun, Marianne. 2001. Who shapes the record: the speaker and the linguist. In P. Newman \& M. Ratliff (eds.), Linguistic Fieldwork, 34-54. Cambridge University Press.

Mithun, Marianne. 2007. What is a language: Documentation for diverse and evolving audiences. Sprachtypologie und Universalienforschung 60(1): 42-55.

Mithun, Marianne. 2014. The data and the examples: comprehensiveness, accuracy, and sensitivity. In T. Nakayama \& K. Rice (eds.), The Art and Practice of Grammar Writing, 25-52. Honolulu: University of Hawai'i Press.

Moore, Robert E. 2006. Disappearing, Inc.: Glimpsing the sublime in the politics of access to endangered languages. Language \& Communication 26: 296-315.

Moreno Cabrera, Juan Carlos. 2008. The written language bias in linguistic typology. Cuadernos de lingüistica del I.U.I. Ortega y Gasset 15: 117-137.

Mosel, Ulrike. 2006a. Fieldwork and community language work. In J. Gippert, N. Himmelmann \& U. Mosel (eds.). Essentials of Language Documentation, 67-86. Berlin: Mouton de Gruyter.

Mosel, Ulrike. 2012a. Morphosyntactic analysis in the field: a guide to the guides. In N. Thieberger (ed.), The Oxford Handbook of Linguistic Fieldwork, 72-89.

Mosel, Ulrike. 2012b. Advances in the accountability of grammatical analysis and description by using regular expressions. In S. Nordhoff (ed.), Electronic Grammaticography, 235250. Honolulu: University of Hawaii Press.

Mosel, Ulrike. 2014. Corpus linguistic and documentary approaches in writign a grammar of a previously undescribed language. In T. Nakayama \& K. Rice (eds.), The Art and Practice of Grammar Writing, 135-157. Honolulu: University of Hawai'i Press.

Musgrave, Simon \& Nicholas Thieberger. 2007. Who pays the piper? Working Together for Endangered Languages: Research challenges and social impacts, XI: 47-54. Foundation for Endangered Languages.

Nathan, David. 2004. Documentary linguistics: alarm bells and whistles? Seminar presentation, SOAS. 23 November 2004.

Nathan, David. 2006. Thick interfaces: mobilizing language documentation with multimedia. In J. Gippert, N. Himmelmann \& U. Mosel (eds.). Essentials of Language Documentation, 363-379. Berlin: Mouton de Gruyter.

Nathan, David. 2013. Progressive archiving: theoretical and practical implications for documentary linguistics. Paper presented at the 3rd International Conference on Language Documentation and Conservation. Available online at http://hdl.handle.net/10125/26115.

Newman, Paul \& Martha Ratliff (eds.). 2001. Linguistic Fieldwork. Cambridge University Press.

Palosaari, Naomi \& Lyle Campbell. 2011. Structural aspects of language endangerment. In P. K. Austin \& J. Sallabank (eds.), The Cambridge Handbook of Endangered Languages, 100-119. Cambridge University Press.

Pawley, Andrew. 1993. A language which defies description by ordinary means. In W. Foley (ed.), The Role of Theory in Language Description, 87-129. Berlin: Mouton de Gruyter.

Payne, Thomas. 1997. Describing Morphosyntax: A guide for field linguists. Cambridge University Press.

Pérez-Báez, Gabriela. 2016. Addressing the gap between community beliefs and priorities and researchers' language maintenance interests. In G. Pérez Báez, C. Rogers \& J. Rosés 
Labrada (eds.), Language Documentation and Revitalization in Latin American Contexts, 165-194. Berlin: de Gruyter.

Rice, Keren. 2001. Learning as one goes. In P. Newman \& M. Ratliff (eds.), Linguistic Fieldwork, 230-249. Cambridge University Press.

Rice, Keren. 2011. Documentary linguistics and community relations. Language Documentation \& Conservation 5: 187-207.

Rice, Keren. 2012. Ethical issues in linguistic fieldwork. In N. Thieberger (ed.), The Oxford Handbook of Linguistic Fieldwork, 407-429. Oxford: Oxford University Press.

Rhodes, Richard, Lenore Grenoble, Anna Berge \& Paula Radetzky. 2006. Adequacy of documentation: a preliminary report to the CELP [Committee on Endangered Languages and their Preservation, Linguistic Society of America].

Robinson, Laura \& James Crippen. 2015. Collaboration: A Reply to Bowern \& Warner's Reply. Language Documentation \& Conservation 9: 86-88.

Salffner, Sophie. 2015. A guide to the Ikaan language and culture documentation. In Language Documentation \& Conservation 9: 237-267.

Samarin, William J. 1967. Field Linguistics: A guide to linguistic field work. New York: Holt, Rinehart \& Winston.

Schiering, René, Balthasar Bickel \& Kristine A. Hildebrandt. 2010. The prosodic word is not universal, but emergent. Journal of Linguistics 46(3): 657-709.

Schmid, Monika. 2011. Language Attrition. Cambridge University Press.

Schultze-Berndt, Eva. 2006. Linguistic annotation. In J. Gippert, N. Himmelmann \& U. Mosel (eds.). Essentials of Language Documentation, 213-251. Berlin: Mouton de Gruyter.

Seifart, Frank, Geoffrey Haig, Nikolaus P. Himmelmann, Dagmar Jung, Anna Margetts \& Paul Trilsbeek (eds.). 2012. Potentials of Language Documentation: Methods, analyses, and utilization. Language Documentation \& Conservation Special Publication No. 3. Honolulu: University of Hawai'i Press.

Sherzer, Joel. 1987. A discourse-centered approach to language and culture. American Anthropologist 89(2): 295-309.

Stebbins, Tonya. 2012. On Being a Linguist and Doing Linguistics: Negotiating Ideology through Performativity. Language Documentation \& Conservation. Vol. 6: 292-317.

Stump, Gregory \& Raphael Finkel. 2013. Morphological Typology. Cambridge University Press.

Tallman, Adam J. R. \& Patience Epps. In press. Morphological complexity, autonomy, and areality in Amazonia. In G. Francesco \& P. Arkadiev (eds.), Morphological Complexity. Oxford: Oxford University Press.

Thieberger, Nicholas. 2009. Steps toward a grammar embedded in data. In P. Epps \& A. Arkhhipov (eds.), New Challenges in Typology: Transcending the borders and refining the distinctions, 389-408. Berlin: Mouton de Gruyter.

Thieberger, Nicholas (ed.). 2012. The Oxford Handbook of Linguistic Fieldwork. Oxford University Press.

Thieberger, Nicholas. 2012. Using language documentation data in a broader context. In Frank Seifart, Geoffrey Haig, Nikolaus P. Himmelmann, Dagmar Jung, Anna Margetts, and Paul Trilsbeek (eds). 2012. Potentials of Language Documentation: Methods, Analyses, and Utilization, 129-134. Honolulu: University of Hawai'i Press.

Thieberger, Nicholas \& Andrea Berez. 2012. Linguistic data management. In N. Thieberger (ed.), The Oxford Handbook of Linguistic Fieldwork, 90-118. Oxford University Press.

Trilsbeek, Paul \& Peter Wittenburg. 2006. Archiving challenges. In J. Gippert, N. Himmelmann \& U. Mosel (eds.). Essentials of Language Documentation, 311-335. Berlin: Mouton de Gruyter. 
Vallejos, Rosa. 2014. Integrating Language Documentation, Language Preservation, and Linguistic Research: Working with the Kokamas from the Amazon. Language Documentation \& Conservation. 8: 38-65

van Driem, George. 2016. Endangered Language Research and the Moral Depravity of Ethics Protocols. Language Documentation \& Conservation 10: 243-252.

Vaux, Bert, Justin Cooper \& Emily Tucker. 2006. Linguistic Field Methods. Eugene, OR: Wipf and Stock.

Warner, Natasha, Quirina Luna, \& Lynnika Butler. 2007. Ethics and revitalization of Dormant languages: the Mutsun language. Language Documentation and Conservation 1(1): 5876.

Wilkins, David. 1992. Linguistic research under Aboriginal control: a personal account of field work in Central Australia. Australian Journal of Linguistics 12: 171-200.

Woodbury, Anthony C. 1998. Documenting rhetorical, aesthetic, and expressive loss in language shift. In L. Grenoble \& L. J. Whaley (eds.), Endangered Languages: Current issues and future prospects, 234-258. Cambridge University Press.

Woodbury, Anthony C. 2003. Defining documentary linguistics. Language Documentation \& Description 1: 35-51.

Woodbury, Anthony C. 2011. Language documentation. In P. K. Austin \& J. Sallabank (eds.), The Cambridge Handbook of Endangered Languages, 159-186. Cambridge University Press.

Woodbury, Anthony C. 2014. Archives and audiences: toward making endangered language documentations that people can read, use, understand, and admire. In D. Nathan \& P. K. Austin (eds.), Language Documentation and Description, vol 12: Special Issue on Language Documentation and Archiving, 19-36. London: SOAS.

Yamada, Racquel-Maria. 2007. Collaborative linguistic fieldwork: Practical application of the empowerment model. Language Documentation \& Conservation 1(2): 257-282. 